\title{
Electrical Stimulation for Nervous System Injury: Research Progress and Prospects
}

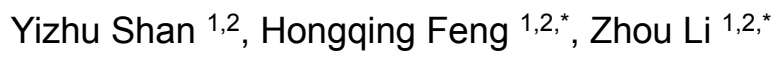 \\ ${ }^{1}$ Beijing Institute of Nanoenergy and Nanosystems, Chinese Academy of Sciences, Beijing 100083, P. R. China. \\ ${ }^{2}$ School of Nanoscience and Technology, University of Chinese Academy of Sciences, Beijing 100049, P. R. China.
}

\begin{abstract}
Nervous system injury can disrupt communications between neurons, leading to loss of basic nerve functions and even paralysis. The clinical prognosis of nervous system injury is usually poor. This adversely affects the physical and mental health of patients and their families, and causes serious economic losses to the society. Due to slow and incomplete healing, the regenerative capacity of the nervous system is limited. Despite development of various biomedical treatment options such as, stem cell transplantation, neurotrophic factors and scaffold application, it is still very difficult to achieve adequate therapeutic effects that can benefit clinical practice. It is worth noting that nervous system

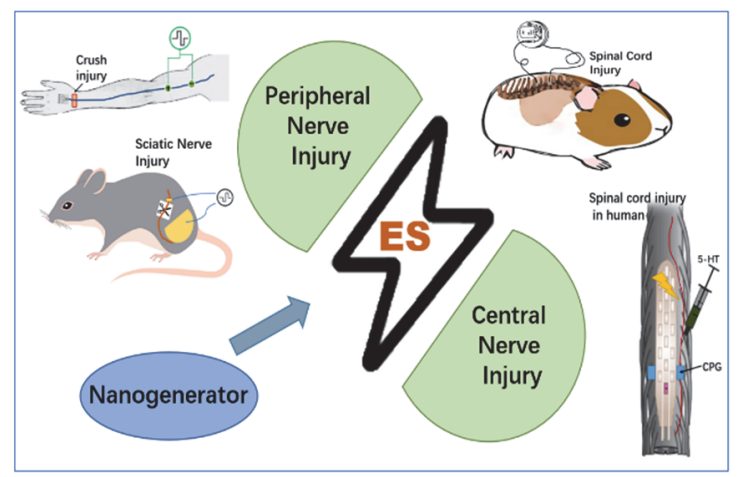
components are closely related to electric fields (EFs), and a fundamental property of neurons is plasticity in response to endogenous and exogenous electrical stimulations. Electrical stimulation has been applied by researchers to induce nerve repair. This review summarizes the progress in research on EFs on neurons and applications of EFs in the treatment of peripheral nerve system and central nerve system injuries, focusing on the methods and effects of electrical stimulation. Research using direct, alternating, and pulsed EFs, with various parameters, has all demonstrated its positive effects on nerve healing and motor function recovery. Research on nanogenerators (NGs), a novel electrical stimulation technology that can convert mechanical energy into electrical energy, has achieved great progress in recent years. In biomedicine, NGs can collect the mechanical energy of human motion and convert it into electrical stimulations without requiring an external power supply, which can lead to significant innovations in electrical stimulation therapy. This review also discusses the recent applications of NGs in the treatment of nervous system diseases. NGs can be used to fabricate miniature, ultrathin, flexible, and biodegradable healthcare devices according to different application scenarios such as in vivo or in vitro. NGs have enabled specific applications in deep brain stimulation, peripheral nerve stimulation, muscle stimulation, and sensory substitution to restore nervous system function. In order to apply electrical stimulation therapy in the clinical setting and improve the quality of life of patients with neurological injuries, further research into stimulation devices and their settings and parameters is highly desirable.
\end{abstract}

Key Words: Electrical stimulation; Nervous system injury; Neural electrode; Functional recovery; Nanogenerator

\footnotetext{
Received: May 14, 2020; Revised: June 10, 2020; Accepted: June 10, 2020; Published online: June 15, 2020.

*Corresponding authors. Emails: fenghongqing@binn.cas.cn (H.F.); zli@binn.cas.cn (Z.L.).

The project was supported by the National Natural Science Foundation of China (81971770, 61875015), the University of Chinese Academy of Sciences, and the National Youth Talent Support Program.

国家自然科学基金(81971770,61875015), 中国科学院大学, 国家万人计划 “青年拔尖” 项目资助

(C) Editorial office of Acta Physico-Chimica Sinica
} 


\title{
电刺激治疗神经系统损伤疾病：研究进展与展望
}

\author{
单义珠 1,2 , 封红青 $1,2,{ }^{*}$, 李舟 $1,2,{ }^{*}$ \\ 1 中国科学院北京纳米能源与系统研究所, 北京 100083 \\ 2 中国科学院大学纳米科学与技术学院, 北京 100049
}

\begin{abstract}
摘要: 神经系统损伤会扰乱神经系统内的通讯, 导致基本神经功能丧失和痽疾, 这不仅给患者本人带来身体和心理上的 极大伤害, 严重影响患者的生活质量, 还会对家庭乃至整个社会造成巨大的经济负担。自 20 世纪 40 年代的研究人员发现 外源电场(EF) 可以诱导神经细胞产生更多的神经突以及引导轴突定向及加速生长之后, 电刺激疗法即被纳入神经损伤的 治疗研究中来, 并在几十年的发展中涌现出很多的优秀成果。本综述讨论了EFs对神经细胞的影响, 以及应用EFs进行 外周神经(PNS)和中枢神经(CNS)损伤的研究进展。在PNS中, EF能够刺激受损肢体神经的再生和功能恢复。在CNS中, 可 以使用 $E F$ 刺激实现轴突再生并恢复患者的行走能力。另外, 近年来关于一种新型的电刺激源一一纳米发电机的研究进展 迅速。纳米发电机是可将机械能直接转换为电能的创新能源器件。将其应用于生物医学领域, 可以收集人体运动的机械 能并直接输出电刺激, 而不再需要外界的电能供应, 这有望为电刺激治疗带来重大的创新和变革。本综述概述了近年来 纳米发电机在神经系统疾病治疗方面的研究进展和应用实例。
\end{abstract}

关键词: 电刺激; 神经系统损伤; 神经电极; 功能修复; 纳米发电机 中图分类号: 0646

\section{Introduction}

In recent years, nervous system injury has attracted more and more attention. The nervous system injury can cause pains and loss of functions to the patients, and do harm to their daily life. The clinical prognosis of the nervous system injury is usually very poor. This will not only adversely affect the physical and mental health of the patients and their families, but also cause serious economic losses to society. In the case of traumatic spinal cord injury (SCI) in nervous system injuries alone, the World Health Organization (WHO) approximates that between 250,000 and 500,000 people suffer from SCI each year ${ }^{1}$. In China, there are approximately 60,000 new cases of SCI each year. The average annual medical cost of each SCI patient is about $\$$ 15,000 to $\$ 30,000$. Depending on the severity of the injury, it is estimated that each patient's lifetime cost will be between $\$$ 500,000 and $\$ 3,000,000^{2}$. In order to treat SCI, many biomedical methods have been carried out, including the use of the growth-promoting effects of neurotrophic factors, elimination of the inhibitory effects of nerve growth inhibitory factors, degradation of glial scars, and neural stem cell transplantation ${ }^{3-6}$. However, due to the slow speed and the incomplete healing of the nervous system, the regenerative capacity of the nervous system is very limited. Despite of the various biomedical treatment methods, it is still impossible to achieve a good therapeutic effect or to be applied to the clinic. What is worth noticing is that the nervous system is closely related to the electric field. In physiological conditions, nerve cells transmit the nerve impulses to fulfill their function by means of action potentials. In pathological conditions, endogenous electric fields can be detected at the damaged nerve and muscle sections ${ }^{7,8}$. Therefore, electrical stimulation could be a unique and promising treatment for nerve injury, and some studies in this field have made impressive progress.

The vulnerability and limited regenerative capacity of the nervous system make it very sensitive to injury. Among the nerve injury, traumatic injury can cause severe damage to the nerve bundles of the entire nervous system. In addition, various factors including long-term diabetes, infection, inflammation, oppression or congenital disease could aggravate the condition of the patients. Due to the genetic limitation of cells or local regeneration inhibition by cell debris and inhibition factors produced by inflammation, the regeneration ability of the

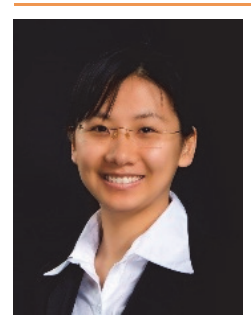

Dr. Hongqing Feng received her Doctor's Degree in Peking University, Beijing. She is currently working as an associate professor at Beijing Institute of Nanoenergy and Nanosystems, CAS. Her research interest includes anti-bacterial technologies and the biomedical applications of nanogenerators.

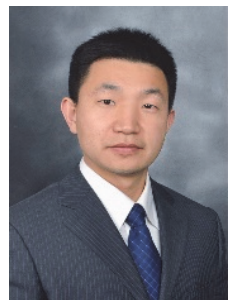

Prof. Zhou Li received his Ph.D. from Peking University in Department of Biomedical Engineering in 2010. Currently, he is a Professor in Beijing Istitute of Nanoenergy and Nanosystems, CAS. His reaserch interests include nanogenerators, in vivo energy harvesters and self-powered medical devices, biosensors. 
nervous system is very limited.

Nervous system injury can be divided into central nervous system injury (CNS) and peripheral nervous system injury (PNS). In PNS and CNS, axons detached from the cell body will undergo Wallerian degeneration after the injury. They will shatter and disintegrate within a few days ${ }^{9}$, and then infiltration of the immune cells leads to debris removal. In PNS, peripheral axons are normally surrounded by supportive Schwann cells. After the injury, the damaged axon retracts from the injury site, then the infiltrating macrophages clear the axon and cell debris. Schwann cells differentiate and begin to express chemical attractants and neurotrophic factors. After the initial stage of inflammation, axons with short distance across will attract the Schwann cells and eventually produce re-dominated nerves to be wrapped again by differentiated Schwann cells ${ }^{10}$. However, when the distance is too large, nerve regeneration will not occur. The axon stump will retract, and neurons may undergo apoptosis. For patients with large-scale nerve damage and large amounts of cell debris and inflammation, subsequent regeneration is incomplete.

However, this mechanism does not work in CNS. Equivalents to Schwann cells - the oligodendrocytes - do not stimulate neural regrowth, and in combination with the hypertrophy of supporting astrocytes and immune cells, the wound environment remains un-supportive for regrowth ${ }^{2}$. If injury occurs, the traumatic environment is more detrimental to regeneration. For example, in a healthy spinal cord, intact nerve bundles are surrounded by oligodendrocytes and supported by astrocytes. But in the acute phase of the injury, severe axons retract toward the soma, and their distal stump and remaining myelinated fragments are engulfed by microglia and infiltrated by macrophages. Damaged oligodendrocytes induce the demyelination of nearby intact axons. In the chronic phase, when the acute inflammatory response has been alleviated, reactive astrocytes proliferate and form dense glial scars. The scars include dense networks of trapped immune cells and extracellular matrix, which inhibit axons regeneration and nerve reconnection.

Nerve cells are closely related to electric fields. During the development of the embryo, maintaining the corresponding potential within a specific range is crucial for the development of a normal nervous system ${ }^{7}$. In the 1940s, Marsh et al. ${ }^{11}$ found that under an electric field of $50-60 \mathrm{mV} \cdot \mathrm{mm}^{-1}$, the neurites of the chicken bulbus grow toward the cathode of the electric field. In addition, some researchers have shown that the electric field of $70 \mathrm{mV} \cdot \mathrm{mm}^{-1}$ can increase the growth rate of chicken neurites ${ }^{12}$. This phenomenon has also been found in many species, such as frogs, xenopus, lampreys, rats, etc. ${ }^{13,14}$.

Because of the connection between these electric fields and repair during the early stage after nerve injury, electrical stimulation has been applied in many researches on nerve repair. In addition, electrical stimulation can be easily combined with nerve reconstruction surgery, which is very convenient for surgeons to operate.

\section{Research progress on nerve injury therapy using traditional electrical stimulators and batteries}

\subsection{Application of electrical stimulation in the repair of PNS injury}

PNS injury is mainly caused by trauma, but there are other factors that can cause this, such as diabetic neuropathy. Although there are possibilities of widespread regeneration in PNS compared to CNS, this kind of regeneration is still incomplete. PNS injury can lead to the loss of function, which is usually accompanied by atrophy of damaged muscles and impaired sensation or persistent neuropathic pain. However, chronic neuropathic pain can be controlled by an electric field, and this method of pain control is better than drugs. In many studies we can see the positive effect of electric field on neural regeneration in PNS.

The basis for applying electrical stimulation to peripheral nerves to promote neural regeneration came from Hoffman's ${ }^{15}$ research firstly. They applied a 50-100 Hz sinusoidal electrical stimulation for 10 to 60 min directly at the root of the L5 spinal cord or the nerve root of the sciatic nerve. It was shown that electrical stimulation accelerated the sprout of axons that partially innervate muscles. Interestingly, it was later discovered that moderate exercise promoted the burst of axons in the nerves that partially dominate the muscles. In terms of the methods of stimulation, one of the most direct way to stimulate nerve regeneration is to implant electrodes directly to the damaged nerve. In a study, in the rat's femoral nerve disruption and early sciatic nerve crush injury, the SD-9 stimulator was used at the early stage to directly stimulate the injured nerve at $3-5 \mathrm{~V}, 20 \mathrm{~Hz}$ for $100 \mathrm{~s}$. Researchers found that electrical stimulation significantly increased the number of crossovers and connections of newborn neurons (Fig. 1a) ${ }^{16}$. Al-Majed et al. ${ }^{17}$ used transected rat sciatic nerve to assess the effects of electrical stimulation. They found that continuous electrical stimulation at $20 \mathrm{~Hz}$ for one hour per day for two weeks at the injury site can significantly shorten the time for the nerve to regain dominance to the muscle. In addition, Huang et al. ${ }^{18}$ studied whether electrical stimulation can enhance the recovery of motor function after nerve injury, and they found that electrical stimulation at $20 \mathrm{~Hz}$ for $1 \mathrm{~h}$ can accelerate exercise capacity recovery after $10 \mathrm{~mm}$ long gap injury. In addition, researchers have implanted a low-intensity continuous current $(1 \mu \mathrm{A})$ stimulation circuit directly into the waist position in a rat model of sciatic nerve crush injury, fixed the anode to the proximal muscle, and fixed the distal cathode below the cathode to the lesion. They found that the application of the electric field can increase the average fiber nerve density after injury and the diameter of the nerve, finally resulting in functional improvement ${ }^{19}$. In addition to implantation of electrodes directly, an alternative approach of electrical stimulation is to 


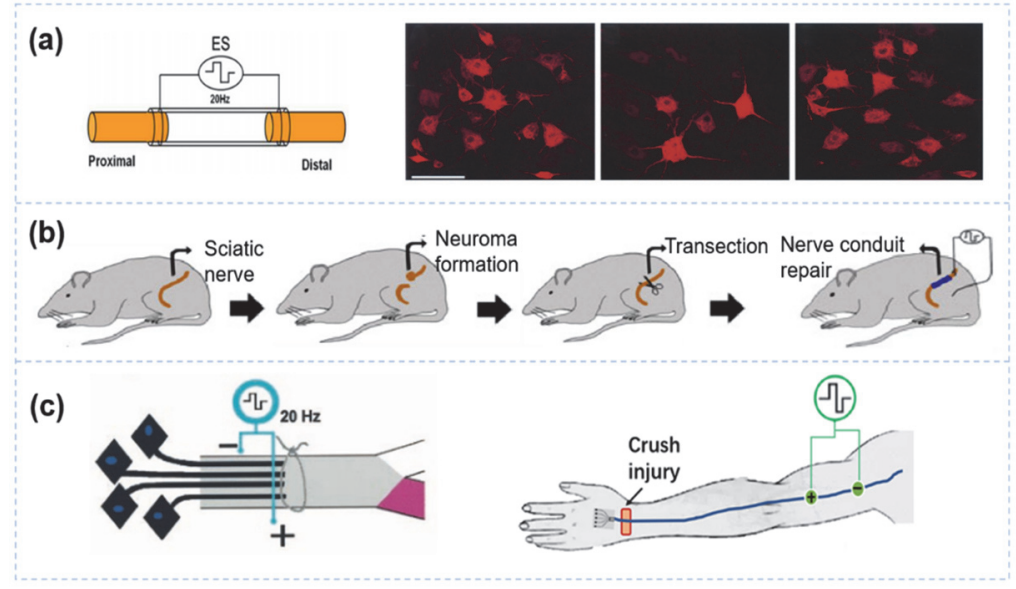

Fig. 1 (a) Brief description of the method of implanting electrodes directly at the damaged nerve. The confocal images show that the number of motor neurons that pass through the repair site is higher in the energized state than the control group ${ }^{16}$. Reprinted with permission from Ref. 16, (c) Society for neuroscience 2002. (b) The method that combines the nerve conduit and electrical stimulation in rats with sciatic nerve injury ${ }^{20}$. Reprinted with permission from Ref. 20, $\odot$ John Wiley and Sons 2013. (c) The method of continuous $20 \mathrm{~Hz}$ electrical stimulation of the repaired femoral nerve just after microsurgical repair of the transected nerve. Adapted from Ref. 27.

implant conductive neural tubes at both ends of a damaged nerve. Huang et al. ${ }^{20}$ transected the sciatic nerve of Sprague Dawley rats, and the repair of nerve injury was delayed for different time durations (2, 4, 12 and 24 weeks). Afterwards brief depolarizing ES was applied to the proximal nerve stump when the transected nerve stumps were bridged with a hollow nerve conduit (5 $\mathrm{mm}$ in length). They found that the diameter and number of regenerated axons, the thickness of myelin sheath, as well as the number of Fluoro-Gold retrograde-labeled motoneurons and sensory neurons were significantly increased by ES (Fig. 1b). They also prepared a conductive polypyrrole/ chitosan stent catheter, and then used this stent catheter to bridge the two ends of a $15 \mathrm{~mm}$ sciatic nerve defect and deliver electrical stimulation at $3 \mathrm{~V}, 20 \mathrm{~Hz}$ for $1 \mathrm{~h}$ through the catheter, which can simultaneously improve motor and sensory functions, along with increased axonal regeneration, myelin formation and BNDF expression ${ }^{21}$.

In terms of nerve stimulation effects, electrical stimulation can accelerate the nerve growth, thus making the nerve reinnervate muscles and restoring motor function as soon as possible ${ }^{22-24}$. In rats, it is generally believed that the recovery of neural function results from the sciatic nerve repair and the activation of compound muscle and sensory potential after electrical stimulation. The specific manifestation is that the rat's hind limbs can flex at normal angles during exercise and can behave plantar extensor reflex when responding to sudden fall ${ }^{25}$. In rabbit studies, continuous electrical stimulation at $4 \mathrm{~Hz}$ to the soleus muscle of rabbits can induce muscle contraction ${ }^{26}$. Although clinical studies on humans are limited, in patients with degenerate intermediate nerves due to severe carpal tunnel syndrome, high-frequency alternating current electric field stimulation generated by implanted electrodes promoted axon regeneration and can improve electrophysiology parameters, but it does not significantly improve the functional parameters (Fig.
$1 \mathrm{c})^{27}$. However, in later studies, $10 \mathrm{~h}$ of electrical stimulation on the median nerve after carpal tunnel release accelerated the nerve control of the large interstitial muscle and restored the sensory compound action potential in advance.

Many groups have been working on the mechanism of electrical stimulation for nerve injury repair. Kirsten et al. ${ }^{28}$ studied the BDNF/Trk B signaling pathway during electrical stimulation therapy. Electric field stimulation can increase the expression of BDNF in damaged neural tissue. Electric fielddriven BDNF expression can in turn increase the expression of HNK-1 carbohydrates present in some cell surface attachment molecules. In addition, studies have shown that using the electric field at $20 \mathrm{~Hz}$ to stimulate damaged nerves for $1 \mathrm{~h}$ can increase the amount of the neuronal cyclic adenosine monophosphate (cAMP) and increase the expression of neurotrophic factors and their receptors in neurons and Schwann cells ${ }^{29-32}$. In addition, electrical stimulation can accelerate and increase neuronal expression of cytoskeletal proteins, including actin and T- $\alpha 1-$ tubulin, and growth-related proteins including $\mathrm{GAP}^{29}$. Electrical stimulation can mediate the release of neurotrophic factors from Schwann cells, especially the release of nerve growth factors, which indicates that stimulated Schwann cells can accelerate the growth of axons of the proximal nerve stump of injured neurons.

\subsection{Application of electrical stimulation in the repair of spinal cord injury}

Spinal cord injury (SCI) is the leading cause of limb paralysis and one of most severe disease among the CNS. In humans, functional recovery after SCI is limited and treatment options are scarce. The only widely accepted treatment option is to apply large doses of steroids early after the injury to relieve tissue damage due to the acute inflammatory response. However, this treatment has many disadvantages. During the spinal cord injury stage, the main limiting factor in functional recovery is that the injured axon can no longer connect to the corresponding site on 
the other side of the damaged area. If the injured spinal nerve does not restore the nerve connection quickly, the axon will contract and the cell body will degenerate. Moreover, the local inflammatory response and glial cell proliferation will form a discontinuous glial scar in the growing axon area, which will also affect the axon reconnection.

The introduction of an electric field at the injured site is a way to promote and guide axon regeneration. The initial inspiration came from the electrical stimulation study of lamprey. After applying a weak stable current of about 10 microamperes to the completely cut spinal cord, enhanced regeneration was observed in the severed giant reticulospinal neurons through fluorescent dye injection and electrophysiological examination (Fig. 2a) ${ }^{33}$. Borgens et al. ${ }^{34}$ implanted a small DC constant current stimulator in a guinea pig with hemisected spinal cord and applied direct current to the spinal cord for 4 weeks or more. They found that electrical stimulation can promote the recovery of a relatively simple tissue reflection of the spinal connectionthe cutaneous trunci muscle (CTM) reflex. Next, they simultaneously implanted the stimulating and recording electrodes in the dorsal spinal cord of guinea pigs. In addition to CTM reflex evaluation, they also tested the vestibulospinal freefall response (FFR). They are the ascending and descending pathways of spinal cord information transmission respectively. It was found that electrical stimulation promoted the recovery of both functions at the same time, which means that electrical stimulation can promote functional repair after spinal cord injury (Fig. 2b, c) ${ }^{35}$.

The type of electrical stimulation required at the spinal cord injury site is also a crucial problem that needs to be considered. Direct-current electric field (DC) has been demonstrated to be effective. In traumatic spinal cord injury, cathodic stimulation leads to histological, electrophysiological and functional improvements, but no significant improvement can be found at the anode ${ }^{36}$. The DC electric field can stimulate axon growth in one direction, but inhibit growth in the opposite direction, so the electric field in a single direction can only promote efferent motor or afferent sensory nerves, instead of both. In order to avoid this problem, researchers developed an oscillating electric stimulator (OFS) which can change the direction every $15 \mathrm{~min}$. This method can provide sufficient time for growth without inducing inhibition in the opposite direction. The OFS was applied in dogs with subacute spinal injury and achieved good results ${ }^{37}$. This study conducted a Phase 1 clinical trial of OFS in people with acutely injured SCI ${ }^{38}$. The researchers implanted the stimulator 3 weeks after the patient was injured and let it work for 15 weeks. They found that electrical stimulation significantly improved sensory sensitivity and that $7 / 9$ of the patients had improved their exercise scores compared to historical data of patients who were not treated. Although some researchers commented on the flaws in the experimental design, the basic conclusions of this experiment are still strong.

Apart from implanting the traditional electrodes to the injury site, epidural electrical spinal cord stimulation has also caught much attention these years. Professor Grégoire Courtine's team at the Federal Institute of Technology in Lausanne (EPFL), Switzerland, has been working on the recovery of exercise capacity in patients with spinal cord paralysis. They carried out a lot of kinematic research in the early stage, and then focused on the research to combine the kinematic characteristics and electrical stimulation. They found that epidural spinal cord stimulation $(40 \mathrm{~Hz})$ of the $\mathrm{S} 1$ spinal cord segment after administration of quinacridine (a non-specific 5-HT2 agonist) will regulate the excitement of rats' flexor and extensor-related spinal neural networks in different ways, which is a qualitatively unique but complementary way to promote exercise in spinal cord injured rats (Fig. 3a) ${ }^{39,40}$. Recently they established a closed-loop neuromodulation system with a multifunctional technology platform ${ }^{41}$. They further combined electronic neuromodulation therapy with spatial selectivity and temporal structure to match the natural dynamics of motor neuron activation. This improved the efficacy of stimulation and improved the quality and vitality of lower extremity movement after spinal cord injury (Fig. 3b) ${ }^{42}$. In 2018, they developed a

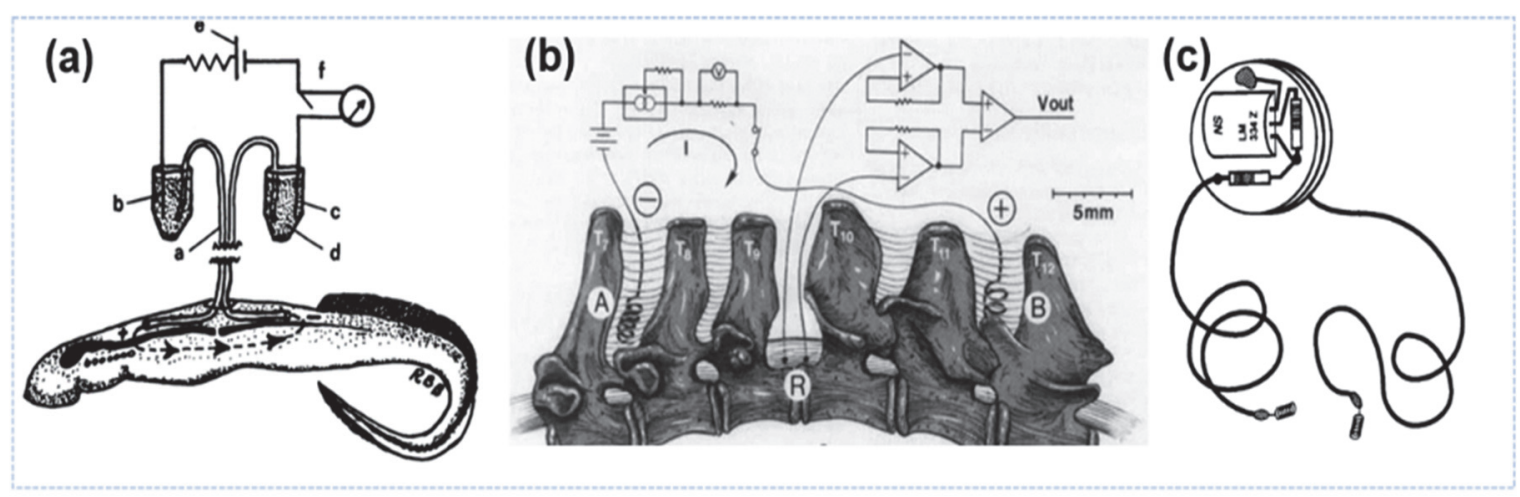

Fig. 2 (a) Surgical and electrical manipulation of lamprey preparation ${ }^{33}$. Reprinted with permission from Ref. 33, (C) The American Association for the Advancement of Science 1981. (b) Brief illustration of the site of the stimulation and record electrodes in guinea pig spinal cord ${ }^{34}$. Reprinted with permission from Ref. 34, (C) John Wiley and Sons 2004. (c) The small DC constant current stimulator used in (b) ${ }^{34}$. 

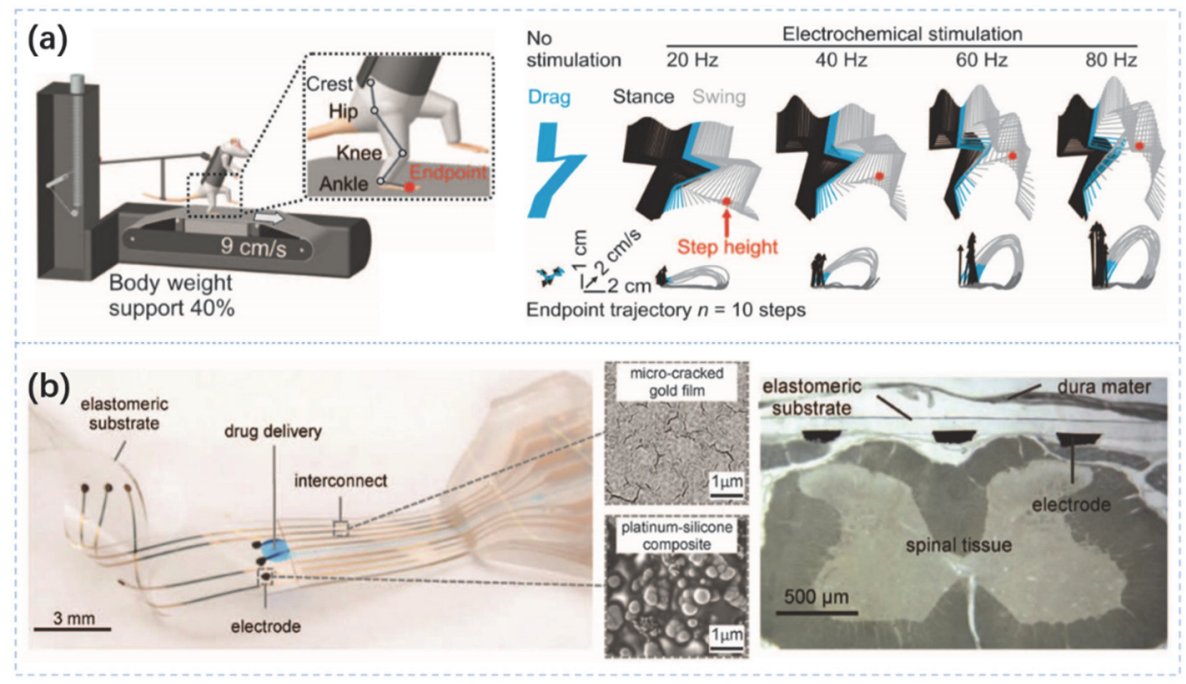

Fig. 3 (a) Rats with complete SCI were positioned bipedally over a treadmill belt using an adjustable body weight support system.

There also showed the modulation of EES frequency tune foot trajectory during locomotion ${ }^{40}$. Reprinted with permission from Ref. 40 ,

(C) The American Association for the Advancement of Science. (b) Optical image of an implant, and scanning electron micrographs of the gold

film and the platinum-silicone composite. Cross-section of an e-dura inserted for 6 weeks in the spinal subdural space ${ }^{42}$. Reprinted with

permission from Ref. 42, (C) The American Association for the Advancement of Science.

targeted spinal cord stimulation nerve technologies that can automatically control walking in individuals who had suffered spinal cord injuries four years ago ${ }^{43}$. At the same time, two other research groups have also shown that the combination of the epidural electrical stimulation and autonomous training can restore the walking ability of patients with spinal cord injury ${ }^{44,45}$.

\section{Research on nerve injury therapy using nanogenerators (NG)}

The electrical stimulation treatments described above all require a battery or power supply. In the past decade, researches on NG, one kind of novel self-powered devices that do not need external power supply, has made great progress. NG can convert mechanical energy into electrical energy. The energy of human movements and activities are also able to drive NG and then output electrical stimulation directly. The development of NGbased electrical stimulation treatments could potentiallybe a promising research direction.

\subsection{Introduction of NG}

During the past ten years, the team of Zhonglin Wang from the Beijing Institute of Nanoenergy and Nanosystems of the Chinese Academy of Sciences has been working on the mechanisms and applications of NG. They first invented the piezoelectric nanogenerators (PENG) that consisted of zinc oxide nanowire array in 2006, which can convert environmental mechanical energy into electrical energy through the piezoelectric effect ${ }^{46}$. Since its inception, the design of PENG has evolved from original $\mathrm{ZnO}$ nanowires and nanocomposites to inorganic thin films. These improvements help to achieve higher output power, better stability and safety of the PENG.

In 2012, they first invented the triboelectric nanogenerator (TENG) ${ }^{47}$. By coupling the triboelectric effect and the electrostatic induction between the two contact materials, TENG can realize rapid conversion of mechanical energy into electrical energy. In addition, by new structure designs and materials innovations, the output power and stability of TENG are constantly improving ${ }^{48-51}$. TENGs have been used to harvest mechanical energy from the environment, including the energy of water waves, vibrations, raindrops, and wind. The unique working mode of TENGs also enables it to be applied in sports and physiological environments to obtain biomechanical energy, including body motion ${ }^{52}$, respiration ${ }^{53}$, and heart beat ${ }^{54}$. The electrical energy transformed by TENGs can also be used in the field of tissue engineering to enhance the neural differentiation of mesenchymal stem cells ${ }^{55}$ and to promote the proliferation and differentiation of osteoblasts ${ }^{56}$. In addition, the study of degradable TENG also suggests a new strategy for the electrical stimulation treatment of nerve injury, which can be degraded and absorbed in the body after the completion of the treatment task. This can avoid the adverse effects such as secondary surgery. Zheng et al. ${ }^{57}$ developed a biodegradable TENG (BD-TENG). The open circuit voltage $\left(V_{\mathrm{OC}}\right)$ of BD-TENG can reach about 40 $\mathrm{V}$ and the corresponding short-circuit current $\left(I_{\mathrm{SC}}\right)$ is about $1 \mu \mathrm{A}$. When powering two interdigitated electrode through BD-TENG, the pulsed electric field generated is $1 \mathrm{~Hz}, 10 \mathrm{~V} \cdot \mathrm{mm}^{-1}$, which can promote the directional growth of nerve cells. BD-TENG can be degraded and absorbed by the body within 90 days, which demonstrated the potential application of BD-TENG for neural regeneration.

\subsection{Application of NG in the treatment of nervous system disease}

Deep brain stimulation (DBS) is a stereotactic method in which microelectrodes are embedded in specific nuclei deeply in the brain. High-frequency electrical stimulation is delivered 
from a pulse generator implanted under the chest skin to change the excitability of the corresponding nuclei. It has been shown to be effective in alleviating various symptoms of neurological and mental illness, including epilepsy, Parkinson's disease, idiopathic tremor, and major depression ${ }^{58}$. Implantable brain stimulators need to work at $3-5 \mathrm{~V}, 130 \mathrm{~Hz}$ and $60 \mathrm{~ms}$ duration, which is higher than artificial pacemakers $(2 \mathrm{~V}, 1 \mathrm{~Hz}$, pulse duration $400 \mathrm{~ms}$ ). In order to achieve self-powered deep brain stimulation, NG can show application possibilities. Kim's research team fabricated flexible single crystal $\mathrm{Pb}(\operatorname{In} 1 / 2 \mathrm{Nb} 1 / 2)$ O3-bb (Mg1/3Nb2/3) O3-PbTiO3 (PIN-PMN-PT:PIMNT) film on a plastic PET substrate and was used for DBS ${ }^{59}$. PIMNT NG produced a maximum current of $0.57 \mathrm{~mA}$ and a power of $0.7 \mathrm{~mW}$ by a human finger bend. This PIMNT-based DBS was used to activate the primary motor (M1) cortex in the rat brain. The generated electrical energy was directly transmitted to the stimulation electrode through the metal wire, and the stimulation electrode was placed at the exact position of the mouse M1 cortex. Each bending cycle of PIMNT NG caused contraction of the forelimb muscles and a 1.5-inch displacement of the right paw (Fig. 4). This work was an important step in doing selfpowered direct DBS through NG which was driven by body movements.

There are also many studies on muscle stimulation and peripheral nerve based on NG. For the application of TENG for direct peripheral nerve stimulation, electrical stimulation can be applied to downstream motor neurons or target muscles to activate muscles and restore some control of the abnormal body. Lee et al. ${ }^{60}$ developed a zigzag-shaped TENG in which several units are stacked together. PET sheets were used for mechanical support, $\mathrm{Cu}$ and PDMS films with nano patterns were used as contact layers. During compression and recovery of the zigzag structure, the $\mathrm{Cu}$ film was in contact with two PDMS layers. Through the configuration of five units in parallel, the $V_{\mathrm{OC}}$ generated by TENG was about $68 \mathrm{~V}$, and the $I_{\text {SC }}$ was about 1.9 $\mu \mathrm{A}$. The nerve stimulation electrodes were made of two layers of flexible polyimide with gold sandwiched between them. The output of TENG driven by human hand tapping was applied to the rat's sciatic nerve through flexible stimulation electrodes. Electrical stimulation caused contraction of the tibialis anterior (TA) and gastrocnemius (GM) muscles and further leg distortions. Electromyograms of TA and GM muscles showed that the frequency of myoelectric potentials was consistent with the stimulation current of TENG. It suggested that TENG electrical stimulation can effectively stimulate nerves and cause leg movements (Fig. 5a). Researchers also developed a new type of water/air-mixed friction nanogenerator (WATENG) ${ }^{61}$ to overcome the current shortcomings of liquid TENG and they achieved effective nerve stimulation (Fig. 5b). By combining the device with a neural interface, selective control of rat leg muscles can be achieved. Functional electrical stimulation (FES) has been used to apply low-energy electrical pulses to artificially contract muscle and improve the body movements of a patient. Whether the TENG stimulator can achieve the high threshold current required for FES is a big problem. Lee et al ${ }^{62}$. designed a new TENG device (D-TENG), which used a diode to amplify the output of the friction NG. The electric current controls the muscles through electrical stimulation (Fig. 5c). Using D-TENG can obtain the exponential current pulse waveform with the best stimulation efficiency, thereby improving the efficiency of direct
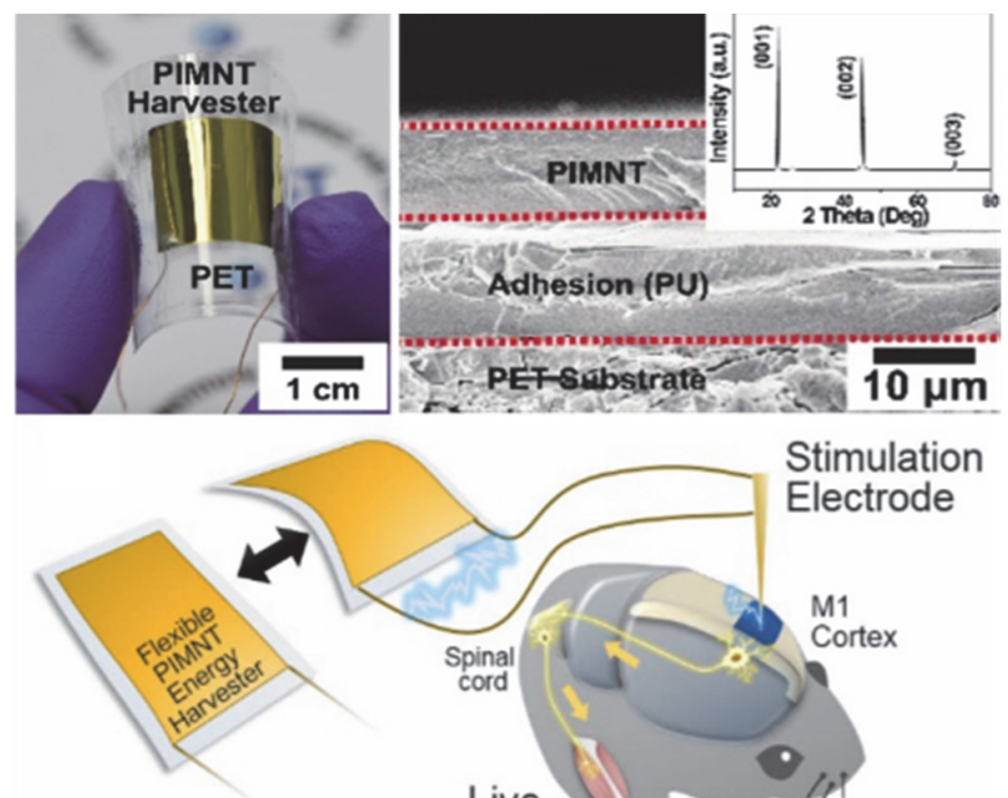

mouse

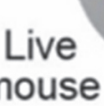

Fig. 4 The real-time self-powered DBS using the flexible PIMNT energy device. The upper part of the picture shows the structure of the PIMNT harvester ${ }^{59}$. Reprinted with permission from Ref. 59, $\odot$ Royal Society of Chemistry. 

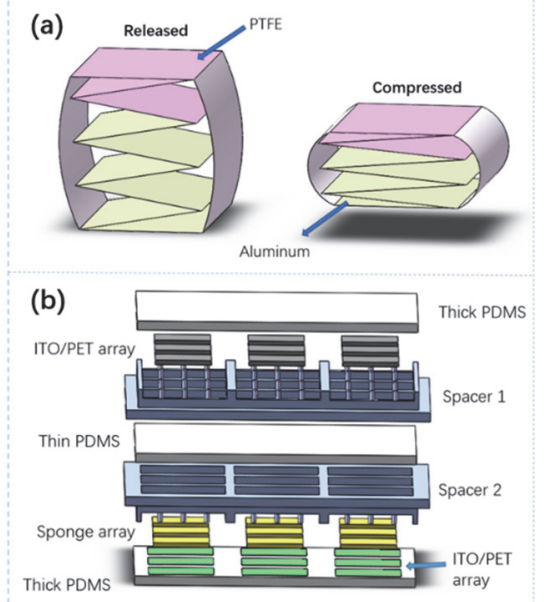

(c)

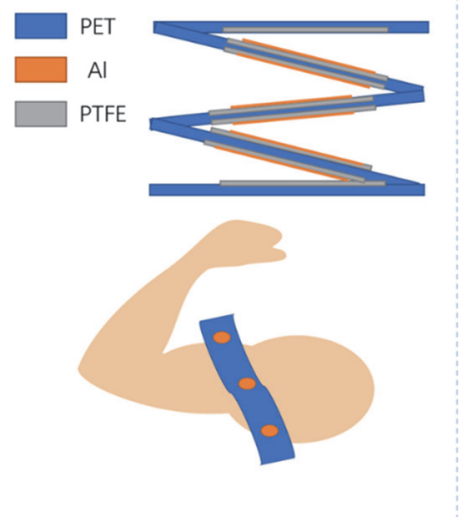

Fig. 5 (a) Schematic diagram of matrix of stimulating ability using stacked TENG. Adapted from Ref. 60. (b) Illustration of layer structure of the WATENG used for neuromodulation. Adapted from Ref. 61. (c) Detailed structure of the D-TENGs for direct

muscle stimulation. Adapted from Ref. 62.

\section{muscle stimulation.}

\subsection{Application of NG for sensory substitution}

Apart from performing nerve electrical stimulation treatment, NG also exhibit some extended functions, including sensory substitution. For example, cochlear implant (CI) can convert the sound into the electrical signal in a certain encoded form by an external speech processor, and directly excite the auditory nerve through the electrode system implanted in the body to restore the hearing function of the deaf. Beker et al. ${ }^{63}$ introduced the design of NG into CI, they developed a piezoelectric energy harvester (PEH) to be implanted on the eardrum or ossicle. The PEH consists of several cantilever beams of predetermined frequency within the hearing band, and generates electrical signals directly from the eardrum vibrations for the auditory nerve stimulation. This system can provide a self-powered hearing substitute to the patient.

In addition, electronic skin has attracted much attention due to its huge application potential in the fields of robotics and medical health. Many researchers made successful application of TENG into this area. Sun et al. ${ }^{64}$ presented a self-powered, flexible, triboelectric sensor (SFTS) patch for finger trajectory sensing and further apply the collected information for robotic control. Combining the 2D-SFTS with the 1D-SFTS, threedimensional (3D) spatial information can be generated and applied to control the $3 \mathrm{D}$ motion of a robotic manipulator. By copying the micro-nano morphology on the surface of natural plants, an interlocking microstructure is formed on the friction layer to enhance the triboelectric effect by Wu's team ${ }^{65}$. The microhair structure of the prepared polymer material improves the electronegativity thus making the sensitivity of the pressure measurement increased by about 14 times. The tactile perception ability of the bionic electronic skin sensor was verified by the characterization of the handshaking pressure and the bending angle of the finger when shaking hands. In addition, Cao et al. ${ }^{66}$ developed a smart soft robot based on TENG and rope (tendon) drive mode. This system has features including fast response, precise control, self-powered pressure and bending sensing, and energy harvesting. TENG has broad application prospects to promote future development of self-powered, advanced prosthetics and wearable devices.

\section{Conclusions and prospects}

With the continuous improvements of stimulation devices, settings and parameters, electrical stimulation as a treatment for neurological injury diseases has become increasingly prominent. This review outlines the application of electrical stimulation in PNS injury and CNS injury, especially in the treatment of spinal cord injury, focusing on the methods and effects of electrical stimulation. In addition, some applications of NG to do neural electrical stimulations are introduced here. The unique selfpowered properties of NG can bring in new solutions for electrical stimulation to treat nerve injuries.

Current electrical stimulation strategies have shown therapeutic potential in animal models, but their ability to mediate clinically important improvements after severe nervous system injury remains elusive. In order to apply electrical stimulation therapy to the clinic and improve the quality of life of patients with neurological injuries, there are several directions that deserve the efforts of researchers.

The first is to integrate the existing various neurotherapy strategies. There have been many advances in the biomedical methods and electrical stimulation methods. These two strategies aim at different treatment mechanisms, but very likely they may have synergistic effects, so we can integrate different treatment methods to improve the effect of treatment. However, the arrangement and combination of the different treatment method is not as easy as imagined. We need to explore the internal mechanisms and fully consider the interactions between their respective mechanisms.

Second, the optimizations of neural electrical stimulation 
devices are also worth working on. The electrical stimulation consists of a complex system, including stimulation, recording, power supply and many other parts. The innovation of each part can promote the clinical transformation of nerve electrical stimulation treatment, and the advances in materials, structure design, and fabrication techniques has created great momentum to the development of this area. In terms of stimulation electrodes, most of the nerve electrodes currently used in clinical practice are metal electrodes with relatively high hardness, which do not match the modulus of biological tissues. Therefore, it is necessary to design electrodes that are more flexible and have better therapeutic effects. The preparation of flexible nerve electrodes can start from choosing thinner, more flexible and elastic materials to fabricate and minimize the electrodes, making them have unprecedented biological integration and modalities ${ }^{67}$. In order to better evaluate the effects of electrical stimulation and adjust the treatment plan flexibly, it is necessary to develop the recording electrodes that can record neuronal activity for a long time. However, the number and density of the recording sites of the microelectrodes need to be improved by at least an order of magnitude to obtain information from large numbers of neurons, which can be achieved by nanofabrication technology ${ }^{68,69}$. The future development of implantable nerve electrodes also largely depends on the continuous innovation of materials and structural design. For example, Fang et al. ${ }^{70}$ developed a neurotassel consisting of an array of flexible and high-aspect ratio microelectrode filaments. A neurotassel can spontaneously assemble into a thin and implantable fiber through elastocapillary interactions when withdrawn from a molten, tissue-dissolvable polymer. Neurotassels offer a new approach for stable neural activity recording. In addition, both the recording and stimulating electrodes need to be mechanically stretchable, capable of following the movement of the nervous system, and it should have a high degree of scalability similar to neural tissue. Duan et al. ${ }^{71}$ reported a stretchable transparent electrode array from carbon nanotube (CNT) web-like thin films that retains excellent electrochemical performance and broadband optical transparency under stretching and highly durable under cyclic stretching deformation, which can record well-defined neuronal response signals. In terms of electrical stimulation power, the emergence of NG has provided a very good solution for solving the energy supply problem of electrical stimulation devices. It can be powered by the energy of the movement by the individual itself, without the need for other external power sources, which can greatly reduce the risk of depleting the implanted electronic device battery. What' more, the rapid development of degradable TENG and degradable electronic devices enables the biological absorbable electronic devices becoming more easily accepted by patients. Implanting them into the body for electrical stimulation treatment will eliminate the need for additional surgery to remove the device. These characteristics are very advantageous for the treatment of neurological diseases with complex tissues and high surgical risks.

The last point is that we need to consider the differences between different individuals. For the better use of the electrical stimulation therapy in clinical practice, tailoring combinations of biological and engineering strategies derived from the identified interactions between their respective mechanisms is very important. With the challenges ahead, future studies could combine sustained efforts across many disciplines, including material science, electronics, mechanical engineering, and neuroscience, to benefit more patients who are suffering from the nervous injury.

\section{References}

(1) Courtine, G.; Sofroniew, M. V. Nat. Med. 2019, 25, 898. doi: 10.1038/s41591-019-0475-6

(2) Haan, N.; Song, B. Adv. Wound Care (New Rochelle) 2014, 3, 156. doi: 10.1089 /wound.2013.0450

(3) Bradbury, E. J.; Khemani, S.; Von, R.; King; Priestley, J. V.; McMahon, S. B. Eur. J. Neurosci. 1999, 11, 3873. doi: 10.1046/j.1460-9568.1999.00809.x

(4) Bregman, B. S.; Kunkel-Bagden, E.; Schnell, L.; Dai, H. N.; Gao, D.; Schwab, M. E. Nature 1995, 378, 498. doi: 10.1038/378498a0

(5) Bradbury, E. J.; Moon, L. D.; Popat, R. J.; King, V. R.; Bennett, G. S.; Patel, P. N.; Fawcett, J. W.; McMahon, S. B. Nature 2002, 416, 636. doi: $10.1038 / 416636 a$

(6) Lu, P.; Jones, L. L.; Snyder, E. Y.; Tuszynski, M. H. Exp. Neurol. 2003, 181, 115. doi: 10.1016/s0014-4886(03)00037-2

(7) Borgens, R. B.; Jaffe, L. F.; Cohen, M. J. Proc. Natl. Acad. Sci. 1980, 77, 4390. doi: 10.1073/pnas.77.7.4390-c

(8) Jenkins, L. S.; Duerstock, B. S.; Borgens, R. B. Dev. Biol. 1996, 178, 251. doi: $10.1006 /$ dbio. 1996.0216

(9) Gaudet, A. D.; Popovich, P. G.; Ramer, M. S. J. Neuroinflammation 2011, 8,110 . doi: $10.1186 / 1742-2094-8-110$

(10) Webber, C. A.; Christie, K. J.; Cheng, C.; Martinez, J. A.; Singh, B.; Singh, V.; Thomas, D.; Zochodne, D. W. Glia 2011, 59, 1503. doi: $10.1002 /$ glia.21194

(11) Marsh, G.; Beams, H. W. J. Cell Comp. Physiol. 1946, 27, 139. doi: $10.1002 /$ jcp. 1030270303

(12) Jaffe, L. F.; Poo, M. M. J. Exp. Zool. 1979, 209, 115. doi: $10.1002 /$ jez. 1402090114

(13) Patel, N.; Poo, M. M. J. Neurosci. 1982, 2, 483. doi: 10.1523/jneurosci.02-04-00483.1982

(14) Hinkle, L.; McCaig, C. D.; Robinson, K. R. J. Physiol. 1981, 314, 121. doi: 10.1113/jphysiol.1981.sp013695

(15) Al-Majed, A. A.; Neumann, C. M.; Brushart, T. M.; Gordon, T. Eur. J. Neurosci. 2000, 12, 4381. doi: 10.1523/jneurosci.20-07-02602.2000 
(16) Al-Majed, A. A.; Tam, S. L.; Gordon, T. J. C. Cell. Mol. Neurobiol. 2004, 24, 379. doi: 10.1023/b:cemn.0000022770.66463.f7

(17) Brushart, T. M.; Hoffman, P. N.; Royall, R. M.; Murinson, B. B.; Witzel, C.; Gordon, T. J. Neurosci. 2002, 22 (15), 6631. doi: 10.1523/jneurosci.22-15-06631.2002

(18) Huang, J.; Hu, X.; Lu, L.; Ye, Z.; Wang, Y.; Luo, Z. J. Neurotrauma 2009, 26, 1805. doi: 10.1089/neu.2008-0732

(19) Mendonça, A. C.; Barbieri, C. H.; Mazzer, N. J. Neurosci. Methods 2003, 129, 183. doi: 10.1016/s0165-0270(03)00207-3

(20) Huang, J.; Zhang, Y.; Lu, L.; Hu, X.; Luo, Z. Eur. J. Neurosci. 2013, 38, 3691. doi: 10.1111/ejn. 12370

(21) Huang, J.; Lu, L.; Zhang, J.; Hu, X.; Zhang, Y.; Liang, W.; Wu, S.; Luo, Z. J. P. O. PLoS One 2012, 7. doi: 10.1371/journal.pone.0039526

(22) Ahlborn, P.; Schachner, M.; Irintchev, A. Exp. Neurol. 2007, 208, 137. doi: $10.1016 /$ j.expneurol.2007.08.005

(23) Gordon, T.; Amirjani, N.; Edwards, D. C.; Chan, K. M. Exp. Neurol. 2010, 223, 192. doi: 10.1016/j.expneurol.2009.09.020

(24) Wong, J. N.; Olson, J. L.; Morhart, M. J.; Chan, K. M. Ann. Neurol. 2015, 77, 996. doi: 10.1002/ana.24397

(25) Singh, B.; Xu, Q. G.; Franz, C. K.; Zhang, R.; Dalton, C.; Gordon, T.; Verge, V. M.; Midha, R.; Zochodne, D. W. J. Neurosurg. 2012, 116, 498. doi: 10.3171/2011.10.JNS11612

(26) Nix, W. A.; Hopf, H. C. Brain research 1983, 272, 21. doi: 10.1016/0006-8993(83)90360-8

(27) Gordon, T.; Chan, K. M.; Sulaiman, O. A.; Udina, E.; Amirjani, N.; Brushart, T. M. J. N. Neurosurgery 2009, 65, A132. doi: 10.1227/01.neu.0000335650.09473.d3

(28) Eberhardt, K. A.; Irintchev, A.; Al-Majed, A. A.; Simova, O.; Brushart, T. M.; Gordon, T.; Schachner, M. Exp. Neurol. 2006, 198, 500. doi: 10.1016/j.expneurol.2005.12.018

(29) Udina, E.; Furey, M.; Busch, S.; Silver, J.; Gordon, T.; Fouad, K. Exp. Neurol. 2008, 210, 238. doi: 10.1016/j.expneurol.2007.11.007

(30) Aglah, C.; Gordon, T.; De Chaves, E. P. J. N. Neuropharmacology 2008, 55, 8. doi: 10.1016/j.neuropharm.2008.04.005

(31) Huang, J.; Ye, Z.; Hu, X.; Lu, L.; Luo, Z. J. G. Glia 2010, 58, 622. doi: $10.1002 /$ glia.20951

(32) Koppes, A.; Zaccor, N.; Rivet, C.; Williams, L.; Piselli, J.; Gilbert, R.; Thompson, D. M. J. Neural. Eng. 2014, 11, 046002. doi: $10.1088 / 1741-2560 / 11 / 4 / 046002$

(33) Borgens, R. B.; Roederer, E.; Cohen, M. J. J. S. Science 1981, 213, 611. doi: $10.1126 /$ science. 7256258

(34) Borgens, R. B.; Blight, A. R.; McGinnis, M. J. S. Science 1987, 238, 366. doi: 10.1126/science. 3659920

(35) Borgens, R. B.; Blight, A. R.; McGinnis, M. E. J. Comp. Neurol.
1990, 296, 634. doi: 10.1002/cne.902960409

(36) Fehlings, M. G.; Tator, C. H. Brain Res. 1992, 579, 32. doi: 10.1016/0006-8993(92)90738-u

(37) Borgens, R. B.; Toombs, J. P.; Blight, A. R.; McGinnis, M. E.; Bauer, M. S.; Widmer, W. R.; Cook Jr., J. R. Restor. Neurol. Neurosci. 1993, 5, 305. doi: 10.3233/RNN-1993-55601

(38) Shapiro, S.; Borgens, R.; Pascuzzi, R.; Roos, K.; Groff, M.; Purvines, S.; Rodgers, R. B.; Hagy, S.; Nelson, P. J. Neurosurg. 2005, 2, 3. doi: 10.3171/spi.2005.2.1.0003

(39) Gerasimenko, Y. P.; Ichiyama, R. M.; Lavrov, I. A.; Courtine, G.; Cai, L.; Zhong, H.; Roy, R. R.; Edgerton, V. R. J. Neurophysiol. 2007, 98 , 2525. doi: 10.1152/jn.00836.2007

(40) Courtine, G.; Gerasimenko, Y.; van den Brand, R.; Yew, A.; Musienko, P.; Zhong, H.; Song, B. B.; Ao, Y.; Ichiyama, R. M.; Lavrov, I.; et al. Nat. Neurosci. 2009, 12, 1333. doi: 10.1038/nn.2401

(41) Wenger, N.; Moraud, E. M.; Raspopovic, S.; Bonizzato, M.; DiGiovanna, J.; Musienko, P.; Morari, M.; Micera, S.; Courtine, G. J. Sci. Transl. Med. 2014, 6, 255 ra133. doi: $10.1126 /$ scitranslmed.3008325

(42) Wenger, N.;Moraud, E. M.; Gandar, J.; Musienko, P.; Capogrosso, M.; Baud, L.; Le Goff, C. G.;Barraud, Q.; Pavlova, N.; Dominici, N.; et al. Nat. Med. 2016, 22, 138. doi: 10.1038/nm.4025

(43) Minev, I. R.; Musienko, P.; Hirsch, A.; Barraud, Q.; Wenger, N.; Moraud, E. M.; Gandar, J.; Capogrosso, M.; Milekovic, T.; Asboth, L.; et al. Science 2015, 347 (6218), 159. doi: 10.1126/science.1260318

(44) Angeli, C. A.; Boakye, M.; Morton, R. A.; Vogt, J.; Benton, K.; Chen, Y.; Ferreira, C. K.; Harkema, S. J. N. Engl. J. Med. 2018, 379, 1244. doi: 10.1056/NEJMoa1803588

(45) Gill, M. L.; Grahn, P.; Calvert, J. S.; Linde, M. B.; Lavrov, I. A.; Strommen, J. A.; Beck, L. A.; Sayenko, D. G.; Van Straaten, M. G; Drubach, D. I.; et al. Nat. Med. 2018, 24, 1677. doi: 10.1038/s41591-018-0175-7

(46) Wang, Z. L.; Song, J. Science 2006, 312, 242. doi: $10.1126 /$ science. 1124005

(47) Fan, F. R.; Tian, Z. Q.; Wang, Z. L. Nano Energy 2012, 1, 328. doi: 10.1016/j.nanoen.2012.01.004

(48) Ouyang, H.; Tian, J. J.; Sun, G. L.; Zou, Y.; Liu, Z.; Li, H.; Zhao, L. M.; Shi, B. J.; Fan, Y. B.; Fan, Y. F.; et al. Adv. Mater. 2017, 29. doi: 10.1002/adma.201703456

(49) Kim, S.; Gupta, M. K.; Lee, K. Y.; Sohn, A.; Kim, T. Y.; Shin, K. S.; Kim, D.; Kim, S. K.; Lee, K. H.; Shin, H. J.; et al. Adv. Mater. 2014, 26, 3918. doi: 10.1002/adma.201400172

(50) Zi, Y.; Lin, L.; Wang, J.; Wang, S.; Chen, J.; Fan, X.; Yang, P. K.; Yi, F.; Wang, Z. L. Adv. Mater. 2015, 27, 2340. 
doi: 10.1002/adma.201500121

(51) Hu, W. T.; Wei, X. L.; Zhu, L.; Yin, D.; Wei, A. M.; Bi, X. Y.; Liu, T.; Zhou, G. M.; Qiang, Y. H.; Sun, X. H. Nano Energy 2019, 57, 600. doi: 10.1016/j.nanoen.2018.12.077

(52) He, C.; Zhu, W.; Chen, B.; Xu, L.; Jiang, T.; Han, C. B.; Gu, G. Q.; Li, D.; Wang, Z. L. ACS Appl. Mater. Interfaces 2017, 9, 26126. doi: 10.1021/acsami.7b08526

(53) Zheng, Q.; Shi, B.; Fan, F.; Wang, X.; Yan, L.; Yuan, W.; Wang, S.; Liu, H.; Li, Z.; Wang, Z. L. Adv. Mater. 2014, 26, 5851. doi: 10.1002/adma.201402064

(54) Zheng, Q.; Zhang, H.; Shi, B. J.; Xue, X,; Liu, Z.; Jin, Y. M.; Ma, Y.; Zou, Y.; Wang, X. X.; An, Z.; et al. ACS Nano 2016, 10, 6510. doi: $10.1021 /$ acsnano.6b02693

(55) Guo, W.; Zhang, X.; Yu, X.; Wang, S.; Qiu, J.; Tang, W.; Li, L.; Liu, H.; Wang, Z. L. ACS Nano 2016, 10, 5086. doi: $10.1021 /$ acsnano.6b00200

(56) Tang, W.; Tian, J.; Zheng, Q.; Yan, L.; Wang, J.; Li, Z.; Wang, Z. L. ACS Nano 2015, 9, 7867. doi: 10.1021/acsnano.5b03567

(57) Zheng, Q.; Zou, Y.; Zhang, Y.; Liu, Z.; Shi, B.; Wang, X.; Jin, Y.; Ouyang, H.; Li, Z.; Wang, Z. L. Sci. Adv. 2016, 2, e1501478. doi: $10.1126 /$ sciadv. 1501478

(58) Mayberg, H. S.; Lozano, A. M.; Voon, V.; McNeely, H. E.; Seminowicz, D.; Hamani, C.; Schwalb, J. M.; Kennedy, S. H. Neuron 2005, 45, 651. doi: 10.1016/j.neuron.2005.02.014

(59) Hwang, G. T.; Kim, Y.; Lee, J. H.; Oh, S.; Jeong, C. K.; Park, D. Y.; Ryu, J.; Kwon, H.; Lee, S. G.; Joung, B.; et al. Energy Environ. Sci. 2015, 8, 2677. doi: 10.1039/c5ee01593f

(60) Lee, S.; Wang, H.; Shi, Q.; Dhakar, L.; Wang, J.; Thakor, N. V.; Yen, S. C.; Lee, C. Nano Energy 2017, 33, 1. doi: $10.1016 /$ j.nanoen.2016.12.038

(61) Lee, S.; Wang, H.; Wang, J.; Shi, Q.; Yen, S. C.; Thakor, N. V.; Lee, C. Nano Energy 2018, 50, 148. doi: 10.1016/j.nanoen.2018.04.004

(62) Wang, H.; Wang, J.; He, T.; Li, Z.; Lee, C. Nano Energy 2019, 63. doi: 10.1016/j.nanoen.2019.06.040

(63) Beker, L.; Zorlu, O.; Goksu, N.; Kulah, H. In Transducers \& Eurosensors XXVII, The 17th International Conference on Solid-State Sensors, Barcelona, Spain, June 16-20, 2013; IEEE : Piscataway, 2013; pp. 1663-1666.

(64) Chen, T.; Shi, Q.; Zhu, M.; He, T.; Sun, L.; Yang, L.; Lee, C. ACS Nano 2018, 12, 11561. doi:10.1021/acsnano.8b06747

(65) Yao, G.; Xu, L.; Cheng, X.; Li, Y.; Huang, X.; Guo, W.; Liu, S.; Wang, Z. L.; Wu, H. Adv. Funct. Mater. 2020, 30, 1907312. doi: $10.1002 /$ adfm. 201907312

(66) Chen, S.; Pang, Y.; Yuan, H.; Tan, X.; Cao, C. Adv. Mater. Technol. 2020, 1901075. doi:10.1002/admt.201901075

(67) Shi, J.; Fang, Y. Adv. Mater. 2019, 31, e1804895. doi: 10.1002/adma.201804895

(68) Lacour, S. P.; Courtine, G.; Guck, J. Nat. Rev. Mater. 2016, 1. doi: 10.1038 /natrevmats. 2016.63

(69) Xu, K; Wang, J. F. Acta Phys. -Chim. Sin. 2020, 36 (12), 2003050. [许可, 王晋芬. 物理化学学报, 2020,36 (12), 2003050] doi: 10.3866/PKU.WHXB202003050

(70) Guan, S.; Wang, J.; Gu, X.; Zhao, Y.; Hou, R.; Fan, H.; Zou, L.; Gao, L.; Du, M.; Li, C.; Fang, Y. Sci. Adv. 2019, 5, eaav2842. doi: $10.1126 /$ sciadv.aav2842

(71) Zhang, J.; Liu, X. J.; Xu, W. J.; Luo, W. H.; Li, M.; Chu, F. B.; Xu, L.; Cao, A. Y.; Guan, J. S.; Tang, S. M.; Duan, X. J. Nano Lett. 2018, 18, 2903. doi: 10.1021/acs.nanolett.8b00087 